\title{
RELECTURA DE LA TEORÍA DE LA INDIVIDUACIÓN EN SøREN KIERKEGAARD Y SU VIGENCIA PARA LA SOCIEDAD ACTUAL ${ }^{1}$
}

\author{
Asunción Herrera Guevara \\ Universidad de Oviedo, España
}

\begin{abstract}
Resumen
El presente artículo argumentará la necesidad de repensar la teoría de la individuación de Kierkegaard. Pretendo analizar esta teoría desde una hermenéutica actual de las obras de Kierkegaard. Los pseudónimos, la comunicación indirecta y la ironía son cuestiones centrales a la hora de reinterpretar el concepto de sujeto en el pensador danés. Finalmente, mostraré cómo un pensamiento tradicional, como el de Søren Kierkegaard, podría ser necesario para solucionar problemas políticos y sociales de nuestras democracias occidentales.
\end{abstract}

Palabras clave: individuo, pseudónimos, comunicación indirecta, democracia occidental.

\section{Abstract}

This paper argues the need to rethink Kierkegaard's theory about the subject. I would like to analyse this theory from a nowadays interpretation of the Works of Kierkegaard. Pseudonyms, indirect communication and irony are central issues to reinterpret the concept of subject in the Danish thinker. Finally, I will show how a traditional thinking in the spirit of Søren Kierkegaard could be necessary for the solution of political and social problems of our Western democracies.

Keywords: subject, pseudonyms, indirect communication, Western democracy.

\section{Introducción}

Richard Rorty, en una de sus obras más influyentes del siglo XX, clasificaba a los filósofos, y a sus filosofías, en periféricos y sistemáticos². Evidentemente,

\footnotetext{
${ }^{1}$ Recibido: 6 de abril de 2016. Aceptado: 16 de abril de 2016.

2 Richard Rorty, La filosofía y el espejo de la naturaleza, Madrid: Ediciones Cátedra, 1983.
} 
toda la caterva de obras y pensamientos, que hubiesen sido relegados por la Academia, pasaban a formar parte de lo periférico. Filósofos como Shaftesbury o Mandeville bien pudieran entrar en este exclusivo club. Todavía se siguen impartiendo clases de Historia de la Filosofía Moral donde estos autores son relegados, en el mejor de los casos, a una pequeña mención. Frente a la Crítica de la razón práctica de Kant o a El sistema de la eticidad de Hegel, bien poco parece que pudieran aportar estos arrinconados autores. Kant y Hegel han sido presentados y estudiados como los dos grandes límites del pensamiento moral a partir de la Modernidad. Ante la pregunta moderna “¿por qué debo ser moral?", la filosofía kantiana y la hegeliana nos ofrecían dos modelos antitéticos difícilmente superables.

Con el paso de la Modernidad, esta hermenéutica de la historia del pensamiento moral ha mostrado sus limitaciones y sus falsedades. No hace falta ser un pensador postmoderno para interpretar nuestro tiempo actual como el resultado de luchas y conflictos entre, al menos, dos maneras dispares de entender la dialéctica de la Ilustración.

Por un lado, somos herederos de una Ilustración diáfana, donde lo filosófico consistía, necesariamente, en construir una algoritmia conceptual que explicase el mundo. Pensadores como Kant o Hegel bien pudieran situarse dentro de esta positiva forma de entender la Modernidad: el entramado de la Razón o el Espíritu nos daban las claves para alcanzar la ansiada emancipación. Los límites de la acción racional se situaban en una Razón transcendental o bien en un Espíritu Absoluto, alejados de la existencia de un sujeto concreto de carne y hueso.

Por otro lado, filósofos del siglo XX, como Adorno y Horkheimer, nos presentaron una dialéctica de la Ilustración diferente 3 . Fueron capaces, utilizando la ironía y la exageración, de mostrar cómo, en los filósofos sombríos de la Ilustración, podíamos encontrar una explicación más veraz del desarrollo de la Modernidad, que en los grandes pensadores diáfanos de la burguesía. Si realmente queremos saber lo que ha sido la dialéctica de la Ilustración, si queremos explicar cómo hemos llegado hasta la situación extrema de violencia vivida en la Segunda Gran Guerra, es necesario -nos dirán los autores de la primera generación de la Escuela de Frankfurtprestar atención y escuchar lo no dicho por la historiografía clásica. Para ello, nada mejor que revisar lo que denunciaron o proclamaron los filósofos proscritos por nuestra diáfana Ilustración. Sade o Nietzsche serán dos de

${ }^{3}$ Theodor Adorno y Max Horkheimer, Dialéctica de la Ilustración, Madrid: Trotta, 1994. 
los ejemplos que analizan los filósofos frankfurtianos ${ }^{4}$.

Søren Kierkegaard, el llamado Sócrates del Norte, se incluiría dentro de un pensamiento ilustrado, que sin renunciar a su auténtico espíritu, y tempranamente en el siglo XIX, es capaz de denunciar una fallida dialéctica de la Ilustración. Esta hermenéutica dolorosa sobre la Modernidad conducirá al pensador danés a ocupar un lugar en las filas de los filósofos periféricos. Pero como he señalado en los párrafos anteriores, con el tiempo se ha visto lo injusto de tal clasificación. Ni Mandeville, por citar un ejemplo, ni mucho menos Kierkegaard son en la actualidad relegados a la periferia.

En el presente, la filosofía kierkegaardiana ha dejado de ser periférica para convertirse en un pilar fundamental, no solo para comprender nuestro desarrollo moderno, sino para explicar muchas de nuestras fallas actuales de vivir la Modernidad. Alguna autoridad filosófica rechazaría esta centralidad de la obra del pensador danés, aduciendo el carácter esencialmente religioso de su obra, en general, y del tema de la individuación, en particular. Ante esta objeción apelaré, en el presente trabajo, a la idea esbozada por Jay Bernstein sobre el ateísmo metódico: el secularista puede extraer contenidos normativos de un pensamiento religioso. Es una exigencia filosófica realizar esta tarea con la obra kierkegaardiana.

En el presente artículo presentaré, en primer lugar, las notas peculiares de Kierkegaard que le condujeron a su "arrinconamiento" (II); a continuación, revisaré la interpretación sesgada que se realizó durante años sobre la obra del pensador danés y que condujo a la exaltación de una fe y de un individuo religioso fundamentalista (III); posteriormente, subrayaré el valor de su teoría de la individuación a la luz de lo explicado en el apartado tercero (IV); y por último, mostraré la aplicación de una teoría de la individuación como la de Kierkegaard ante los problemas sociales y políticos que vivimos en las actuales democracias occidentales $(\mathrm{V})$.

\section{Kierkegaard, pensador enmascarado}

\section{A. Pensador postmetafísico y religioso: su rechazo al Sistema}

Kierkegaard no fue un pensador diáfano de la Ilustración. Su forma de hacer filosofía lo distanció de los grandes metafísicos y lo unió a las filas de escritores religiosos. Él mismo insiste en sus obras, y en su Diario

${ }^{4}$ Véase "Excursus II: Juliette, o Ilustración y moral” en Adorno y Horkheimer, Dialéctica de la Ilustración, pp. 129-163. 
intimo, en ser considerado un pensador religioso ${ }^{5}$. Nos encontramos ante un pensador postmetafísico que se define como un autor religioso. Ambas caracterizaciones, lejos de contradecirse se apoyan mutuamente.

En numerosos escritos encontramos su alejamiento del pensamiento metafísico dominante en su época, el hegelianismo ${ }^{6}$. El estudio de Adorno sobre Kierkegaard nos pone sobre aviso de la, a veces burda, interpretación sobre Hegel que realiza el danés:

La interpretación de Hegel por parte de Kierkegaard es muy problemática y, por lo demás, sorprendentemente semejante a la de Marx. El concepto central hegeliano contra el que se afana (el de mediación) fue torpemente mal interpretado por Kierkegaard. En Hegel, la mediación se produce a través de los extremos. Que el concepto salga de sí mismo para convertirse en su contradicción significa, en lenguaje hegeliano, que el concepto se ha automediatizado. Kierkegaard, en cambio, interpretó a la mediación hegeliana como una etapa intermedia entre los conceptos, como una suerte de compromiso moderador. Es factible que, bajo la influencia de Trendelenburg, Kierkegaard introdujera en Hegel el concepto aristotélico del justo medio, del mesótes. La panacea que ofrece contra Hegel, en cambio, ha sido tomada literalmente de este: el salto cualitativo proviene del prólogo a la Fenomenología del espiritu ${ }^{\top}$.

Teniendo en cuenta estas apreciaciones adornianas, es decir, que en ocasiones interpreta mal a Hegel y que en otras tantas se acerca a su pensamiento, me centraré en las principales razones que le condujeron al rechazo del hegelianismo. Tal rechazo se repite en numerosos escritos. De hecho, encontramos referencias constantes en su Diario íntimo; pero será en una de sus obras designada, por él mismo, como filosófica, dónde leeremos los mayores ataques. Me refiero, evidentemente, a Migajas filosóficas ${ }^{8}$. Con el planteamiento inicial del Problema de Lessing, Kierkegaard cuestionará, en esta obra, la posibilidad de que una verdad histórica y contingente

${ }^{5}$ Søren Kierkegaard, Diario intimo, trad. de M. A. Bosco y S. Rueda, Buenos Aires: Santiago Rueda, 1955.

${ }^{6}$ Gran parte de los estudios sobre Kierkegaard recogen su rechazo a la filosofía hegeliana. Cabe citar entre otros los trabajos deJames, Collins, Elpensamiento de Kierkegaard, México: FCE, 1958; Harald Höffding, Kierkegaard, Madrid: Revista de Occidente, 1930; Theodor Adorno, Kierkegaard, Caracas: Monte Ávila, 1969; Javier Urdanibia, (coord.), Los antihegelianos: Kierkegaard y Shopenhauer, Barcelona: Anthropos, 1990 y Léon Chestov, Kierkegaard y la filosofía existencial, Buenos Aires: Editorial Sudamericana, 1965.

${ }^{7}$ Theodor Adorno, Kierkegaard, p. 268.

${ }^{8}$ Véase Søren Kierkegaard, Migajas filosóficas, trad. de Rafael, Larrañeta, Madrid: Trotta, 1997. 
pueda fundamentar una verdad eterna; pretensión que el pensador danés ve claramente en el Sistema hegeliano'. Un Sistema que lo explica todo y da cabida a todo. Frente a Hegel, Kierkegaard no se conforma con alcanzar una verdad objetiva, esta tal vez quepa en el Sistema. El Sócrates del Norte pretende partir de una verdad subjetiva para, posteriormente, alcanzar la verdad cristiana y para este fin no puede valerse del Sistema.

De este modo, la filosofía del pensador danés se aleja de la filosofía hegeliana en un punto central: la doctrina de Kierkegaard no se fija en Sistema alguno. Criticará contundentemente la construcción de un Sistema, de una algoritmia conceptual que explique el mundo:

Con la mayoría de los filósofos sistemáticos y sus sistemas ocurre lo mismo que con aquel que luego de construir para sí un castillo, habita en un pajar. Ellos no viven dentro de sus enormes edificios sistemáticos. En el campo del espíritu esto constituye una objeción capital. Las ideas de un hombre deben de ser su propia morada; de lo contrario, peor para ellas ${ }^{10}$.

Si el Sistema no es el instrumento que le permitirá a Kierkegaard alcanzar la verdad cristiana, es preciso renunciar al lenguaje que utiliza el Sistema. Este segundo paso se concreta con su abandono de la comunicación directa, en casi la totalidad de sus obras, y en la asunción de la comunicación indirecta. Veamos las consecuencias.

\section{B. Comunicación indirecta, ironía y pseudonimia}

Hegel utilizará la comunicación directa para transmitir una verdad objetiva. Frente a esta pretensión, Kierkegaard empleará la comunicación indirecta para informar de una verdad subjetiva, que escapa al Sistema. Johannes Climacus, en Migajas filosóficas y en el Postcriptum no científico a Migajas filosóficas, mostrará frente a los hegelianos, que la subjetividad es la verdad y que el cristianismo no es una doctrina o una mera especulación. Por lo tanto, para transmitir la verdad del cristianismo no podemos emplear los métodos de transmisión de una verdad objetiva ${ }^{11}$.

${ }^{9}$ El problema de Lessing es planteado como preámbulo bajo el título de la obra. Climacus nos dice: "¿Puede darse un punto de partida histórico para una conciencia eterna? ¿Cómo puede tener este punto de partida un interés superior al histórico? ¿Puede basarse la felicidad eterna en un saber histórico?” en Climacus, Migajas filosóficas, p. 21.

${ }^{10}$ Søren Kierkegaard, Diario intimo, p. 147.

${ }^{11}$ En el esquema de Hegel encontramos, dirá Kierkegaard, una identificación 
La comunicación indirecta será la vía adecuada para transmitir una verdad subjetiva. Los dos instrumentos de los que se sirve Kierkegaard, en este uso de la comunicación indirecta, serán la ironía y la pseudonimia. El Sócrates del Norte se familiarizó tempranamente con la ironía. Su tesis doctoral versa, como su nombre indica, Sobre el concepto de ironía ${ }^{12}$. La pretensión de Kierkegaard, como buen ironista, será combatir con la ironía el "decadente espíritu de su época". Los grandes ironistas, comenzando por Sócrates, emplean este recurso a fin de resquebrajar lo establecido, con el fin de mostrar a sus conciudadanos las grietas y fisuras de un mundo que no se nos presenta -tomando unas palabras de Kierkegaard-taly como debiera ser amado ${ }^{13}$.

Junto a la ironía, el otro gran recurso kierkegaardiano será el empleo de pseudónimos. Los primeros estudios sobre Kierkegaard, tales como los de Harald Höffding, Walter Lowrie, David F. Swenson y Eduard Geismar,

entre pensamiento (razón) y ser (existencia). El pensador danés rechaza sin más esta identificación. Se puede dar en el terreno de la especulación, pero para un existente tal identidad nunca será la verdad. Tomando a Descartes como referente, considerará que la auténtica identificación se da entre la conciencia y la existencia. Ahora bien, la conciencia es definida como contradicción entre realidad e idealidad; por lo tanto, la existencia refleja esta misma contradicción, la existencia es duda. La verdad quedaría situada no en el mundo objetivo, sino en el mundo del devenir, de la contradicción y la duda, junto a la interioridad y la subjetividad. Para una explicación detallada de la verdad en Kierkegaard véase Rafael Larrañeta, La interioridad apasionada. Verdad y amor en Sören Kierkegaard, Salamanca: San Esteban, 1990.

${ }^{12}$ Søren Kierkegaard, Sobre el concepto de ironía, trad. de Darío González y Begonya Saez, Madrid: Trotta, 2000.

${ }^{13}$ Un claro ejemplo del uso y del valor didáctico de la ironía lo encontramos en La rotación de cultivos (la citaré siguiendo la edición francesa en la que aparece con el título L'Assolement). Esta obra está incluida dentro de O lo uno o lo otro (1843). Obra en la que Kierkegaard emplea el pseudónimo de Víctor Eremita y es dividida en dos partes. La rotación de cultivos pertenece a la primera parte y su autor es llamado A, un individuo estético y arrogante que se opone a B, el asesor Wilhem, autor de la segunda parte de la obra y que vive en el plano ético. El individuo A como buen esteta intenta superar el aburrimiento al que le conduce su esteticismo. Como muestra de la ironía kierkegaardiana reproduciré la propuesta descabellada de A: “(que el Estado) emita un préstamo de quince millones, no para emplearlo en un reembolso, sino para diversiones públicas [...] Todo será gratis: gratis las entradas del teatro, gratis las prostitutas [...] Nadie será propietario de un inmueble Se hará una excepción la mía. Me reservo guardar cien escudos todos los días en un banco de Londres; por una parte, porque menos no me sería suficiente, por otra, porque yo soy el padre de la idea, y, por último, porque no puedo saber si cuando los quince millones se agoten, tendré otra idea”, Søren Kierkegaard, "L'Assolement” en Ou bien ...ou bien, trad. de O. Prior y M. H. Guignot, París: Gallimard, 1999, p. 224. La traducción es mía. 
no tuvieron en cuenta el verdadero alcance y significado del uso de los pseudónimos ${ }^{14}$. A raíz de la publicación del ensayo de Josiah Thompson, "El maestro de la ironía" en 1972, los hermenéutas kierkegaardianos prestaron atención al papel de la pseudonimia y dejaron de despreciar, en su mayor parte, palabras tan clarificadoras, como las que aparecen en una de las pocas obras firmadas por el pensador danés ${ }^{15}$; me refiero a Mi punto de vista como escritor religioso ${ }^{16}$. En esta obra se insta a poner el nombre del pseudónimo cuando se cita una obra del autor. Se distancia de sus pseudónimos. Reconoce haberlos empleado como un rodeo necesario para alcanzar su objetivo: enseñar cómo ser un auténtico sí mismo, o lo que es lo mismo para Kierkegaard, cómo ser un auténtico cristiano en la Cristiandad. Se presenta a sí mismo como un reformador y educador en miniatura, que necesita engañar para realizar su tarea educativa. De este modo se enmascara con sus pseudónimos. Su pensamiento no puede ser extraído, literalmente, de lo que sus pseudónimos firman ${ }^{17}$. Pero ¿qué significa "engañar" a la hora de transmitir una verdad? La respuesta nos la da el mismo Kierkegaard:

¿Qué significa, pues, "engañar"? Significa que no se debe empezar directamente con la materia que uno quiere comunicar, sino empezar aceptando la ilusión del otro hombre como buena. Así, pues, [...], no se debe empezar de este modo: yo soy cristiano; tú no eres cristiano. $\mathrm{Ni}$ tampoco se debe empezar así: estoy proclamando el cristianismo; y tú estás viviendo dentro de categorías puramente estéticas. No, se debe empezar de este modo: vamos a hablar de estética. El engaño estriba en el hecho de que uno habla de ella simplemente para llegar al tema religioso ${ }^{18}$.

El pensador danés utilizará los pseudónimos como el instrumento válido, de comunicación indirecta, empleado por quien educa dentro de la Cristiandad. Es necesario un rodeo, un engaño: hablar y mostrar cómo se vive dentro de las categorías estéticas y éticas para, en última instancia, mostrar los límites

${ }^{14}$ Véase Eduard Geismar, Søren Kierkegaard, Güterlosh, 1925; Harald, Höffding, Søren Kierkegaard, Madrid: Revista de Occidente, 1930 y Walter Lowrie, Kierkegaard, London: Oxford University Press, 1938.

${ }^{15}$ Cfr. Josiah Thompson, "The master of Irony" in Kierkegaard. A Collection of Critical Essays, New York: Doubleday, 1972.

${ }^{16}$ Søren Kierkegaard, Mi punto de vista como escritor religioso, trad. de José Miguel Velloso, Buenos Aires: Aguilar, 1980.

${ }^{17}$ En este sentido, como mantengo en otros escritos, sería más correcto hablar de auténticos heterónimos en la obra kierkegaardiana.

${ }^{18}$ Søren Kierkegaard, Mi punto de vista como escritor religioso, pp. 62-63. 
de esas existencias, y la plenitud de una existencia religiosa que nos permita ser lo que el poder ha querido que seamos: auténticos sí mismos, auténticos cristianos en la Cristiandad.

Interpretar las obras, firmadas por pseudónimos, como el pensamiento verdadero de Kierkegaard sería un error ${ }^{19}$. El auténtico pensamiento de un autor tan difícil de desenmascarar, como es el del Sócrates del Norte, lo entresacamos de las obras firmadas por él, y de las firmadas por un pseudónimo, Anti-Climacus. Puede parecer extraño tras lo dicho poner el acento en uno de los pseudónimos, pero la razón de ello también la encontramos en una de las obras de Kierkegaard. Se nos dirá que Anti-Climacus es un pseudónimo excepcional. Todos los pseudónimos anteriores -Johannes de Silentio, Johannes Climacus o el Juez Wilhem, por citar tres ejemplos significativos- se situaban en una esfera existencial alejada de la esfera del auténtico cristianismo, e incluso por debajo del propio Kierkegaard. Ahora bien, Anti-Climacus, el cristiano extraordinario, expresa una idealidad más alta. En palabras del pensador danés:

Más tarde, sin embargo, apareció un nuevo pseudónimo, Anti-Climacus. Pero el hecho de que sea un pseudónimo (como el nombre mismo AntiClimacus indica) requiere que haya que considerarlo más bien como una señal de parada. Todos los pseudónimos anteriores están por bajo del 'autor edificante' (Kierkegaard): el nuevo pseudónimo representa una pseudonimidad más alta. Sin embargo, hay que entender que la 'parada' se realiza señalando un ideal más alto ${ }^{20}$.

Veamos cómo afecta esta caracterización kierkegaardiana al tema de la fe.

\section{La fe en Kierkegaard: de Johannes de Silentio a Anti-Climacus}

Temor y temblor ha sido interpretada como la obra emblemática para entender el significado de la fe en el pensador danés ${ }^{21}$. Tras lo mostrado en el apartado anterior veo necesario matizar e incluso rectificar esta hermenéutica.

${ }^{19}$ Esta es la razón por la cual escribo en las obras citadas, junto al nombre del pensador danés, el nombre del pseudónimo que firma la obra. Me parece necesario para entender el verdadero significado de la obra e, igualmente, lo veo necesario si queremos ser fieles a los deseos de Kierkegaard.

${ }^{20}$ Søren Kierkegaard, Mi punto de vista como escritor religioso, p. 154. El segundo paréntesis es mío.

${ }^{21}$ Søren Kierkegaard, Temor y temblor, trad. de Vicente Simón Merchán, Madrid: Tecnos, 1987. 
En 1990 aparece una obra que polemiza directamente con las tradicionales interpretaciones de la obra kierkegaardiana. Me refiero a la obra de M. Holmes Hartshorne, Kierkegaard: el divino burlador ${ }^{22}$. El autor apoyándose en el ensayo de Josiah Thompson, citado con anterioridad, interpreta la obra pseudónima del pensador danés como una burla y engaño hacia el lector ${ }^{23}$. La tesis de Harsthorne se encuentra bien documentada, pero considero que su conclusión final es exagerada. Kierkegaard no se burla del lector, y si le engaña lo hace tan solo en el sentido, que el mismo autor reconoce en Mi punto de vista como escritor religioso. Desde mi interpretación, sus obras pseudónimas no mantienen los auténticos pensamientos kierkegaardianos sobre la fe o la estética, pero sí muestran las luchas y las contradicciones que el mismo Kierkegaard padeció a lo largo de su vida, en su intento de alcanzar la verdad cristiana. Como he comentado con anterioridad, todas sus obras firmadas por pseudónimos son un rodeo para llegar a ser un sí mismo. La intención del rodeo es educar y reformar a sus conciudadanos en la vivencia del cristianismo, dentro de la Cristiandad.

Así pues, Temor y temblor, obra firmada por Johannes de Silentio, es una obra estética: con ella se da un rodeo para llegar a saber lo que es la auténtica fe. Está firmada por un no creyente, Johannes de Silentio, quien mostrará al lector cómo un hombre, que todavía no es creyente, entiende el misterio de la fe. Estaríamos ante un primer peldaño en la vivencia de la verdadera fe.

En Temor y temblor se plantea la posibilidad de suspensión de la ética cuando nos adentramos en la esfera religiosa: el "pathos" que hay en ella es terrible. Johannes de Silentio intenta comprender cómo Abraham, el caballero de la fe, tuvo fe:

(Abraham) creyó que Dios no le exigiría a Isaac, pero al mismo tiempo estaba dispuesto a sacrificárselo, si así estaba dispuesto. Creyó en virtud del absurdo, pues no había lugar para humanas conjeturas, y era absurdo pensar que si Dios le exigía semejante acto, pudiera, momentos después, volverse atrás ${ }^{24}$. 1992.

${ }^{22}$ Véase Holmes Hartshorne, M., Kierkegaard: el divino burlador, Madrid: Cátedra,

${ }^{23}$ Más extrema es la interpretación que hace de las obras de Kierkegaard el estudioso danés Johannes Slök. Según este intérprete, la independencia de los pseudónimos dificulta cualquier posible investigación sobre Kierkegaard e incluso encuentra un pseudónimo oculto en los Discursos edificantes. Discursos donde no se recurre a la pseudonimia. Véase Johannes Slök, Kierkegaard's Univers, Kövenhavn: Centrum, 1983.

${ }^{24}$ Søren Kierkegaard, Temor y temblor, p. 28. 
'Temor' y 'temblor' son categorías de esta fe vista por un no creyente: Abraham, para Johannes de Silentio, cree en virtud del absurdo. Junto a este sentimiento de horror religiosus se añaden, a la figura del caballero de la fe, dos movimientos contradictorios: uno de resignación infinita -ofrece lo más preciado para él, Isaac, por mandato de Dios-, y otro de esperanza -Isaac le será restituido.

Angustia, resignación infinita, temor, temblor y absurdo son las categorías que pueblan el templo anímico de Abraham. La lectura de Johannes de Silentio va más lejos y dilucida sobre la verdadera exigencia de una fe vivida dentro de tales categorías: para cumplir el mandato divino se exige al caballero de la fe la suspensión teleológica de la ética. Desde el punto de vista ético, Abraham sería juzgado como un parricida. ¿Es esta la verdadera fe del creyente? Si tenemos en cuenta el papel de los pseudónimos, la respuesta es negativa. Lo que significa la vivencia de la auténtica fe hemos de buscarlo en las obras y discursos firmados por Kierkegaard, y por el pseudónimo excepcional, el cristiano extraordinario, Anti-Climacus.

El silencio que ha de guardar el caballero de la fe no solo es una forma violenta de escapar de la acción moral (suspensión teleológica de la ética) sino, como defiende Harsthorne, es la misma actitud que tendría un fanático, que se cree llamado por Dios, para justificar una acción que queda fuera de la esfera ética ${ }^{25}$.

Un no creyente, como Johannes de Silentio, puede comprender la fe como vivencia de lo absurdo, la angustia, el temor y el temblor; pero la fe del creyente no es la fe en el absurdo, sino en Dios, o lo que es lo mismo para Kierkegaard, la fe es vivida por el auténtico creyente como amor. La fe transforma el absurdo. En las obras firmadas por Anti-Climacus y en Las obras del amor -escrito firmado sin pseudónimo- encontramos las claves de esta nueva caracterización de la fe ${ }^{26}$.

El verdadero significado de la fe debemos encontrarlo en el individuo que llega a ser un auténtico cristiano; tal sí mismo será Anti-Climacus. En La enfermedad mortal Anti-Climacus da las claves para transfigurar el absurdo,

${ }^{25}$ Una idea central que se discute en Temor y temblor es la diferencia esencial entre un héroe trágico como Agamenón y el caballero de la fe, Abraham. El primero puede hablar ante su pueblo, su mujer y su hija Ifigenia, con la intención de justificar el sacrificio que está dispuesto a hacer. Por el contrario, Abraham debe permanecer en silencio, nunca sería comprendido.

${ }^{26}$ Véase Søren Kierkegaard, Las obras del amor, $1^{\mathrm{a}}$ y $2^{\mathrm{a}}$ parte, trad. de D. G. Rivero, Madrid: Guadarrama, 1965; Søren Kierkegaard, La enfermedad mortal, trad. de D. G. Rivero, Madrid: Guadarrama, 1969. 
la desesperación y la angustia: como posibles abolidos son elementos de la fe, pero si dan la espalda a la fe son pecado ${ }^{27}$. "Mantener firme la posibilidad" es la definición correcta de la fe ${ }^{28}$. Firmeza ante la posibilidad de abolir el absurdo, el temor, el temblor, la desesperación y la angustia a través de una dialéctica existencial que se mueve a saltos.

Anti-Climacus señala el camino para abolir la desesperación, la enfermedad mortal: admitir que llegar a ser sí mismo significa llegar a ser lo que el Poder (Dios) ha querido que seamos. Si damos este paso, estaremos reduplicando el cristianismo, estaremos siendo auténticos cristianos; habremos aceptado el imperativo ético-religioso del cristiano extraordinario: "Tú debes amar". En Las obras del amor desglosa Kierkegaard esta categoría -el amor cristiano, verdadero y eterno- diferenciándola del amor natural o pagano.

El círculo se cierra. Kierkegaard nos ha llevado, dando un rodeo, al verdadero significado de la fe cristiana: el amor. Dios es amor y solo nos pareceremos a Él amando al prójimo. El amor cristiano conoce la existencia del prójimo: "si no existiese el deber de amar, tampoco existiría el concepto 'prójimo'; solamente cuando se ama al prójimo queda eliminado el egoísmo de la predilección y protegida la igualdad de lo eterno en el amor" ${ }^{29}$.

Explicaré en el siguiente apartado cómo esta nueva caracterización de la fe, que nos lleva a un imperativo ético-religioso que impone lo que no se puede imponer, el amor, condiciona la interpretación de la teoría de la individuación del pensador danés.

\section{La teoria de la individuación bajo el prisma del imperativo ético-religioso}

Como buen pensador existencial, Kierkegaard se adentra en diferentes niveles de existencia para explicar cómo alcanzar el objetivo de ser un auténtico cristiano, es decir, cómo llegar a ser un sí mismo. Tradicionalmente se distinguen, en su obra, tres niveles de existencia: el nivel estético, el ético y el religioso. Los pseudónimos empleados por el pensador danés obedecen a tal clasificación.

Un ejemplo de ello lo encontramos en Etapas en el camino de la vida por Hilarius Encuadernador publicada en $1845^{30}$. La obra se subdivide en

\footnotetext{
${ }^{27}$ Véase Søren Kierkegaard, La enfermedad mortal, pp. 143-SS.

${ }^{28}$ Søren Kierkegaard, Diario intimo, p. 245.

${ }^{29}$ Søren Kierkegaard, Las obras del amor, $1^{a}$ parte, p. 104.

${ }^{30}$ Søren Kierkegaard, Etapas en el camino de la vida, trad. de J. Castro, Buenos Aires:
} 
verdaderas esferas de existencia, cada una de ellas representan diferentes modos de vivir. La primera parte corresponde a la esfera estética, lleva por título In vino veritas, y es firmada por William Af-ham; la segunda parte titulada Observaciones sobre el matrimonio lleva el sello indiscutible del Asesor Wilhelm, y se inscribe dentro del nivel ético; finaliza con una parte dedicada al estadio culmen, el religioso, en donde nos encontramos con Frater Taciturnus y su disertación Culpable o no culpable.

En la teoría de la individuación de Kierkegaard, los sujetos no son algo estéticos, algo éticos o algo religiosos. Se encuentran en uno o en otro estadio, sin más, y se mueven de un estadio a otro no gradualmente, sino a saltos $^{31}$.

La gran preocupación de Kierkegaard será determinar cómo el sujeto de carne y hueso puede alcanzar la auténtica fe -la explicada por AntiClimacus y vivida en las obras del amor- o, lo que es lo mismo, cómo llegar a ser sí mismo. Mostrará la imposibilidad de ser un auténtico individuo en la esfera estética. El prototipo de sujeto estético será Johannes el Seductor, quien firmará, entre otras obras, Diario de un seductor ${ }^{32}$. Posee todas las cualidades del Don Juan de Mozart, es pura sensualidad. La existencia de un individuo de tales características tendrá un límite. Una vida vivida en la sensualidad estética no podrá evitar el aburrimiento: todo quehacer se parecerá al anterior. La vida se siente como tedio, repetición y monotonía. Vivida al máximo el sujeto cae en la desesperación.

El sujeto ético presenta dos diferencias existenciales en relación al individuo estético: por un lado, no puede dejar de ver el mundo bajo las categorías de bien y mal; por otro, la elección tiene un gran peso en su existencia, mientras que para el Don Juan no tiene sentido elegir. No se trata de elegir entre una cosa u otra, hablamos de una elección existencial: querer llegar a ser sí mismo. El sujeto ético asume la responsabilidad de su propia biografía. El prototipo de tal individuo adoptará el nombre, en la obra de Kierkegaard, del Asesor Wilhelm, a quien se le añaden los rasgos de la ética kantiana. Podríamos pensar que este es el auténtico sí mismo, pero nada más lejos de la pretensión del pensador danés. Los sujetos de la esfera ética también se encontrarán con un límite: la repetición de la norma

Santiago Rueda, 1951.

${ }^{31}$ La categoría de salto tiene gran peso en la obra kierkegaardiana. La mayoría de los comentaristas ven en el empleo de esta categoría otra forma de oponerse a Hegel y a categorías hegelianas como la mediación.

${ }^{32}$ Søren Kierkegaard, Diario de un seductor, trad. de D. G. Rivero, Barcelona: Ediciones Destino, 1988. 
y el hábito les puede conducir a la desesperación. Intentarán salir de la desesperación particularizándose como individuos, haciéndose únicos. El problema residirá en la absolutización que de sí mismo realiza el sujeto ético. El individuo ético enarbolando su autonomía no necesitará de otros ni de Otro. Ni tan siquiera es capaz de salir de la desesperación, se lo impide el hecho de no aceptar ser lo que el Poder ha querido que sea.

En la esfera religiosa sí encontramos al auténtico sí mismo y, por ende, al verdadero cristiano Anti-Climacus. Como expuse con anterioridad, él será capaz de escapar de la desesperación, de la angustia o del absurdo tras la aceptación de ser lo que el Poder ha querido que sea. ¿Cómo se realiza este salto a la esfera religiosa? A través de las obras del amor.

El propio Kierkegaard reconocerá, en su Diario íntimo, la rigurosidad de un estadio como el vivido por Anti-Climacus. Ante tal rigurosidad, podríamos entresacar de sus obras un cuarto estadio denominado el ético-religioso. El proceso para alcanzar la autenticidad, en este nuevo estadio, pasa por la actuación en el mundo visible. Más concretamente, será necesario obrar entre los demás hombres. Las obras del amor marcan el camino a seguir. El sujeto de carne y hueso, si quiere ser un auténtico individuo, ha de moverse en el estadio ético-religioso, y debe cumplir los dos imperativos ético-religiosos que anuncia Kierkegaard: "Tú debes amar" y "Tú debes creer". Debemos amar al prójimo. El pensador danés define al prójimo como la completamente incognoscible distinción entre hombre y hombre. El amor, entendido como deber, posibilita el salto a la fe: debemos amar al prójimo porque a través de este amor es como nos relacionamos y semejamos a Dios y, en definitiva, se llega a ser un sí mismo.

\section{Conclusiones: el sujeto kierkegaardiano en el presente}

El tono de esta última parte del artículo cambiará intencionadamente. En los apartados anteriores, me he centrado en las notas que hacen del pensamiento kierkegaardiano un pensamiento cuanto menos difícil de interpretar. Hasta tal punto esto es así que durante un gran período de tiempo, e incluso en algunas interpretaciones actuales, se adhirió, el pensamiento de Kierkegaard, a una concepción fundamentalista de la fe como la presente en Temor $y$ temblor. Con la hermenéutica defendida en este artículo, la fe en el pensador danés, no puede ser confundida con la asunción por parte de un fanático de una llamada de Dios. La fe es amor: "Tú debes amar" se convierte en el imperativo ético-religioso del auténtico cristiano. Más aún, un sujeto tal no 
puede suspender teleológicamente la ética. Necesita de ella para poder vivir en esa esfera ético-religiosa, que le permite el desarrollo de su autenticidad.

En Kierkegaard, el verdadero cristiano coincide con el auténtico sí mismo. El sujeto que ama a Dios, a través del prójimo, ha llegado a ser lo que el Poder ha querido que sea. Es un individuo valiente que, pese a las comodidades de las esferas estética y ética, saltará a la esfera ético-religiosa. No se conforma ni con la mera sensualidad de lo estético, ni con seguir la rutinaria norma o hábito. Asume la elección existencial y, en un acto que podríamos llamar heroico, construirá su sí mismo superando la angustia y la desesperación.

En el presente apartado pretendo resaltar el valor del pensamiento de Kierkegaard, y más concretamente de su teoría de la individuación, para la filosofía del presente. Es necesario revitalizar a los grandes pensadores y entresacar de sus enseñanzas los contenidos normativos que nos pueden ser válidos hoy. En el caso de Kierkegaard nos encontramos siempre con una reticencia o un problema añadido; no se trata tan solo de la dificultad a la hora de interpretar su obra, sino de enfrentarnos a un pensamiento religioso. Esta caracterización no puede ser un impedimento a la hora de acercar su obra al presente. Ni tan siquiera para los que encuadramos el pensamiento filosófico actual dentro de un pensamiento claramente postmetafísico y postreligioso.

El filósofo norteamericano Richard Jay Bernstein, al definir el ateísmo metódico, subraya la figura del secularista que busca un núcleo racional e inmanente de convicciones religiosas, pero sin renunciar a la autoridad decisiva de la razón secular ${ }^{33}$. Siguiendo esta línea de investigación del ateísmo metódico, el filósofo secular puede traducir un pensamiento religioso y entresacar su núcleo racional.

Esbozaré un intento de tales características en el pensamiento de Kierkegaard en un punto que me parece central: la filosofía de hoy necesita reflexionar sobre un nuevo sujeto, conformador de la actual ciudadanía en las sociedades democráticas.

Vivimos un siglo plagado de conflictos tanto en las sociedades occidentales comofuera de ellas. Tal vez habría que cuestionar esta separación y siendo coherentes con el proceso llamado globalización -a pesar de las diferencias entre Norte y Sur, entre países desarrollados y países en vías de desarrollo o entre Occidente y Oriente-, se debería aceptar que todo está

${ }^{33}$ Véase Richard J. Bernstein, Radical Evil: A Philosophical Interrogation, Cambridge: Blackwell Publishers, 2002. 
vinculado con todo. Tres ejemplos claros de la nueva lógica conectiva los encontramos en la crisis ecológica, que incumbe a todo el planeta, en el terrorismo, que se ha hecho más internacional que nunca, y en los sistemas financieros del presente.

Los retos ecológicos, políticos y económicos son de tal envergadura que vislumbro la necesidad de un nuevo proyecto ilustrado. Me explico. Hemos vivido dos intentos de Ilustración, y digo intentos porque los considero fallidos ${ }^{34}$. La primera Ilustración viene acompañada de los grandes pensamientos de los siglos XVIII y XIX. Las tres grandes Ilustraciones europeas - la inglesa, la francesa y la alemana cada una con su impronta- nos hacen herederos de importantes relatos de emancipación. Ese era el objetivo último de la Ilustración: emancipar, sacar al sujeto de su autoculpable minoría de edad.

El análisis llevado a cabo por Adorno y Horkheimer en Dialéctica de la Ilustración me parece tan aterrador como certero:

La Ilustración, en el más amplio sentido de pensamiento en continuo progreso, ha perseguido desde siempre el objetivo de liberar a los hombres del miedo y constituirlos en señores. Pero la tierra enteramente ilustrada resplandece bajo el signo de una triunfal calamidad. El programa de la Ilustración era el desencantamiento del mundo. Pretendía disolver los mitos y derrocar la imaginación mediante la ciencia [...] A partir de ahora la materia debe ser dominada por fin sin la ilusión de fuerzas superiores o inmanentes, de cualidades ocultas. Lo que no se doblega al criterio del cálculo y la utilidad es sospechoso para la Ilustración [...] La ilustración es totalitaria ${ }^{35}$.

El entrelazamiento de Ilustración y dominio ha conducido a la alienación de la sociedad y de sus sujetos. La desesperanza parece traslucirse de la obra de los primeros frankfurtianos, quienes pretendían explicar lo inexplicable: la atrocidad y la violencia que habían alcanzado, en pleno siglo XX, las naciones ilustradas.

Un segundo intento de Ilustración se sitúa en los años 60 del siglo $\mathrm{XX}$, y está relacionado con la emergencia de importantes movimientos sociales, que defendieron los derechos civiles y políticos de una gran parte de la población occidental. Me refiero a los movimientos en defensa de los derechos de los afroamericanos o a la segunda ola feminista. Junto a este

${ }^{34}$ Para un desarrollo pormenorizado de este planteamiento véase Asunción Herrera Guevara, Ilustrados o bárbaros, Madrid: Plaza y Valdés, 2014.

35 Theodor Adorno y Max Horkheimer, Dialéctica de la Ilustración, pp. 59-62. 
activismo pro derechos se inicia, con una fuerza inusual, el replanteamiento de nuestras relaciones con la naturaleza, en general, y con los animales no humanos en particular.

Al igual que la primera, esta segunda Ilustración también resultó fallida. La mayor parte de los problemas globales de hoy tienen que ver con la asignación de derechos -en una gran parte del planeta a las mujeres, a los inmigrantes o a los refugiados- y con la pésima gestión que hemos realizado de nuestra relación con el mundo natural.

Todas las épocas que pretendieron ser ilustradas necesitaron un tipo especial de individuo. El individuo kantiano es el prototipo de la primera Ilustración. En la segunda, se exigía un individuo kantiano que debería comulgar con el respeto a la diferencia. Actualmente necesitamos vivir un nuevo proyecto de Ilustración, la tercera, llevada a cabo por un individuo capaz de dar el salto, y situarse más allá de la estrechez de los límites nacionales. Un individuo que, en analogía con el sujeto kierkegaardiano, sea capaz de saltar por encima de las comodidades estéticas y éticas que le brinda el llamado primer mundo.

Tal sujeto no solo tendrá rasgos del individuo ético kantiano, ha de ampliar esta caracterización apreciando el valor de la diferencia, de lo otro, y extendiendo esa otredad incluso al mundo de la naturaleza. Un sujeto con un nuevo concepto de justicia, menos parroquiano y nacional y más global e internacional. Eso sí, al igual que el ente kierkegaardiano, solo podrá llevar a buen puerto esta tercera Ilustración, si en su esfera de existencia el otro es lo importante ${ }^{36}$. A pesar de las interpretaciones solipsistas, la comunidad era un elemento crucial para el pensador danés. El ente solo se podía realizar a través de los demás, en comunidad ${ }^{37}$. De igual modo, el sujeto ilustrado de hoy debe realizar su titánica tarea inmerso en una sociedad que le será bastante hostil, pero como bien dice Kierkegaard en Temor y temblor:

Si el resultado alcanzado podrá o no llenar de júbilo al mundo, es algo que no sabe de antemano, pues no logrará tal conocimiento hasta que el acto haya sido consumado, y con todo, no será esto lo que le convertirá en héroe, sino el haber sido capaz de empezar.

Esta es mi propuesta: un nuevo sujeto, con valores kierkegaardianos secularizados, capaz de iniciar una tercera Ilustración. Tal vez la propuesta

${ }^{36}$ Recuérdese que en Kierkegaard el otro adopta la categoría de prójimo.

${ }^{37}$ Evidentemente no se puede deducir de la crítica kierkegaardiana a la turba, un rechazo de la comunidad. La comunidad es condición necesaria para la existencia del auténtico sí mismo. Véase Søren Kierkegaard, Las obras del amor, op. cit. 
sea tildada de ambiciosa, pero como dice un personaje de una novela es necesario pensar como un héroe para actuar como un bumano decente.

\section{Bibliografía}

Kierkegaard, Søren, Etapas en el camino de la vida, trad. de J. Castro, Buenos Aires: Santiago Rueda, 1951.

- Diario intimo, trad. de M. A. Bosco y S. Rueda, Buenos Aires: Santiago Rueda, 1955.

L Las obras del amor, trad. de D. G. Rivero, Madrid: Guadarrama, 1965.

— Diario de un seductor, trad. de D. G. Rivero, Barcelona: Ediciones Destino, 1988.

— La enfermedad mortal, trad. de D. G. Rivero, Madrid: Guadarrama, 1969.

- Mi punto de vista como escritor religioso, trad. de José Miguel Velloso, Buenos Aires: Aguilar, 1980.

— Temor y temblor, trad. de Vicente Simón Merchán, Madrid: Tecnos, 1987.

— Migajas filosóficas, trad. de Rafael Larrañeta, Madrid: Trotta, 1997.

_- Ou bien... ou bien, trad. de O. Prior y M. H. Guignot, París: Gallimard, 1999.

- Sobre el concepto de ironía, trad. de Darío González y Begonya Saez Tajafuerce, Madrid: Trotta, 2000.

Adorno, Theodor, Kierkegaard, Caracas: Monte Ávila, 1969.

Adorno, Theodor y Horkheimer, Max, Dialéctica de la Ilustración, Madrid: Trotta, 1994.

Bernstein, Richard J., Radical Evil: A Philosophical Interrogation, Cambridge: Blackwell Publishers, 2002.

Cañas, José Luis, Søren Kierkegaard. Entre la inmediatez y la relación, Madrid: Trotta, 2003.

Chestov, Léon, Kierkegaard y la filosofía existencial, Buenos Aires: Editorial Sudamericana, 1965.

Collins, James, El pensamiento de Kierkegaard, México: FCE, 1958.

García Pavón, Rafael y Dobre, Catalina, Søren Kierkegaard y los ámbitos de la existencia, México: Bonobos Editores, 2011.

Geismar, Eduard, Søren Kierkegaard, Güterlosh, 1925.

Guerrero Martínez, Luis, La verdad subjetiva. Søren Kierkegaard como escritor, México: Universidad Iberoamericana, 2004. 
Hartshorne, M. Holmes, Kierkegaard: el divino burlador, Madrid: Cátedra, 1992. Herrera Guevara, Asunción, La historia perdida de Kierkegaard y Adorno, Madrid: Biblioteca Nueva, 2005.

Herrera Guevara, Asunción, Ilustrados o bárbaros, Madrid: Plaza y Valdés, 2014. Höffding, Harald, Kierkegaard, Madrid: Revista de Occidente, 1930.

Larrañeta, Rafael, La interioridad apasionada. Verdad y amor en Sören Kierkegaard, Salamanca: San Esteban, 1990.

Larrañeta, Rafael, La lupa de Kierkegaard, Salamanca: Editorial San Esteban, 2002. Lowrie, Walter, Kierkegaard, London: Oxford University Press, 1938.

Rorty, Richard, La filosofía y el espejo de la naturaleza, Madrid: Ediciones Cátedra, 1983.

Slök, Johannes, Kierkegaard's Univers, Kövenhavn: Centrum, 1983.

Suances, Manuel, Søren Kierkegaard, Madrid: UNED, 2003.

Thompson, Josiah, "The master of Irony" in Kierkegaard. A Collection of Critical Essays, New York: Doubleday, 1972.

Urdanibia, Javier (coord.), Los antibegelianos: Kierkegaard y Schopenhauer, Barcelona: Anthropos, 1990. 